\title{
Correlation of Power Consumption for Several Kinds of Mixing Impellers
}

\author{
Haruki Furukawa, ${ }^{1}$ Yoshihito Kato, ${ }^{1}$ Yoshiro Inoue, ${ }^{2}$ Tomoho Kato, ${ }^{1}$ \\ Yutaka Tada, ${ }^{1}$ and Shunsuke Hashimoto ${ }^{2}$ \\ ${ }^{1}$ Department of Life and Materials Engineering, Nagoya Institute of Technology, Gokiso-cho, Showa-ku, Nagoya-shi, \\ Aichi 466-8555, Japan \\ ${ }^{2}$ Division of Chemical Engineering, Graduate School of Engineering Science, Osaka University, 1-3 Machikaneyama-cho, \\ Toyonaka-shi, Osaka 560-8531, Japan
}

Correspondence should be addressed to Yoshihito Kato, kato.yoshihito@nitech.ac.jp

Received 28 November 2011; Revised 26 January 2012; Accepted 3 February 2012

Academic Editor: See-Jo Kim

Copyright (๑) 2012 Haruki Furukawa et al. This is an open access article distributed under the Creative Commons Attribution License, which permits unrestricted use, distribution, and reproduction in any medium, provided the original work is properly cited.

The authors reviewed the correlations of power consumption in unbaffled and baffled agitated vessels with several kinds of impellers, which were developed in a wide range of Reynolds numbers from laminar to turbulent flow regions. The power correlations were based on Kamei and Hiraoka's expressions for paddle and pitched paddle impellers. The calculated correlation values agreed well with experimental ones, and the correlations will be developed the other types of impellers.

\section{Introduction}

Mixing vessels is widely used in chemical, biochemical, food, and other industries. Recently scientific approaches were developed by Inoue and Hashimoto $[1,2]$. On the other hand, the power consumption is the most important factor to estimate mixing performance and to design and operate mixing vessels.

To estimate the power consumption, the correlation of Nagata et al. [3] has traditionally been used. However, this correlation was developed for two-blade paddle impellers, which do not always have the same numerical values of power consumption as those of multiblade impellers. Kamei et al. $[4,5]$ and Hiraoka et al. [6] developed the new correlation of the power consumption of paddle impellers, which is more accurate than Nagata's.

However, the new correlation also cannot reproduce the power consumption for other types of impellers. The propeller- and Pfaudler-type impellers are used for low-viscosity liquid and solid-liquid suspensions, and the propeller type has been widely used in vessels ranging from portable type to large tanks. Kato et al. [7] developed a new correlation of power consumption for propeller- and Pfaudler-type impellers based on the correlations of Kamei and Hiraoka.

The power consumption for an anchor impeller was measured by Kato et al. $[8,9]$ in a wide range of Reynolds numbers from laminar to turbulent flow regions. In the laminar region, the power number of the anchor was reproduced by the correlations of Nagata and Kamei et al. by considering the anchor as a wide paddle impeller. In the turbulent region, it was reproduced by the correlation of Kamei et al. without the correction of the parameters.

In this paper, the authors reviewed the power correlations developed by authors in unbaffled and baffled mixing vessels with several kinds of impellers.

\section{Experimental}

Figure 1 shows a photograph of mixing impellers used in this work. Figure 2 shows the geometry of impellers with symbols. The mixing vessel used is shown in Figure 3. The vessels for the measurement of power consumption are flat-bottom cylindrical ones of inner diameter $D=185$ and $200 \mathrm{~mm}$. 


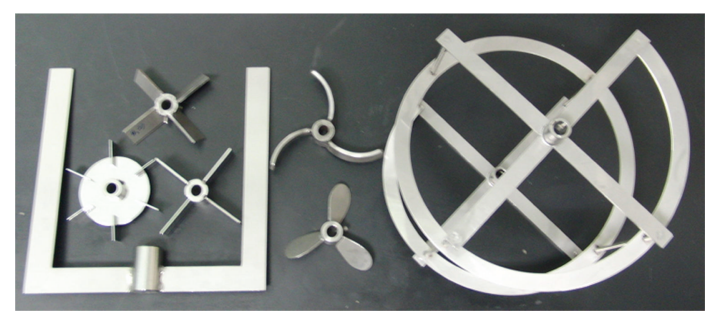

FIGURE 1: Photograph of several kinds of mixing impellers.

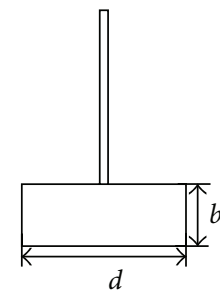

(a) Paddle

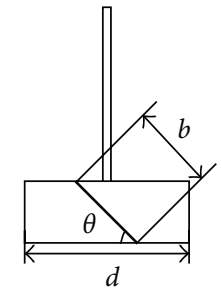

(b) Pitched paddle

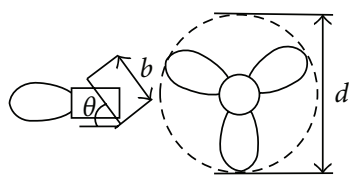

(d) Propeller

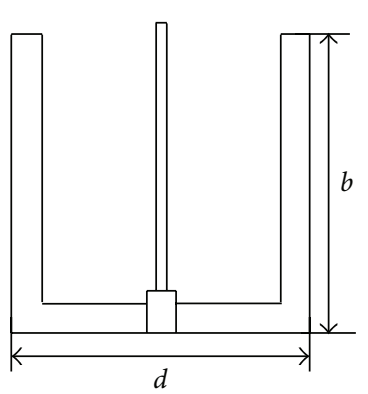

(f) Anchor

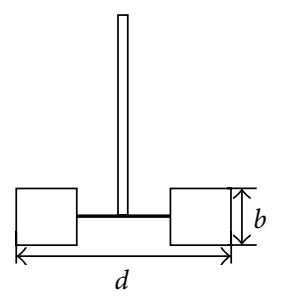

(c) Rushton

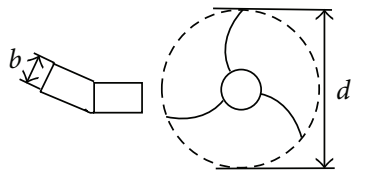

(e) Pfaudler

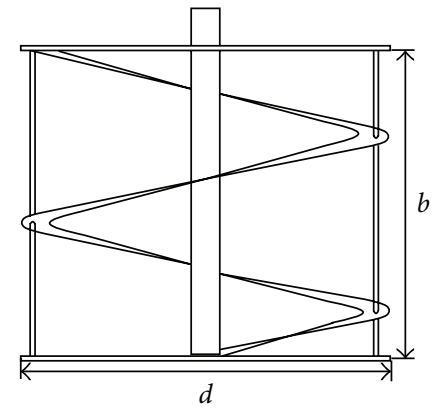

(g) Helical ribbon
FIgURE 2: Geometry of mixing impellers.

Three kinds of baffled conditions were mainly used: unbaffled, four baffles of $B_{W}=D / 10$ (i.e., the standard baffled condition), and fully baffled. The baffles were plate type. The paddle, pitched paddle, Rushton turbine, propeller, and pfaudler impellers were symmetrically set up at one-half the level of the liquid depth $(C / H=0.5)$. The pfaudler, anchor, and helical-ribbon impellers were set up slightly above the bottom (bottom clearance of $1 \mathrm{~mm}$ ).

For the measurement of the power consumption, the liquids used were desalted water and varying starch-syrup solutions $(\mu=0.003-13 \mathrm{~Pa} \cdot \mathrm{s})$. The liquid was filled to the height equal to the vessel diameter $(H=D)$.

The power consumption $P(=2 \pi n T)$ was measured with the shaft torque $T$ and rotational speed $n$ by using two types of torque meter (ST-1000 and ST-3000, Satake Chemical Equipment Mfg., Ltd.). The range of rotational speed was

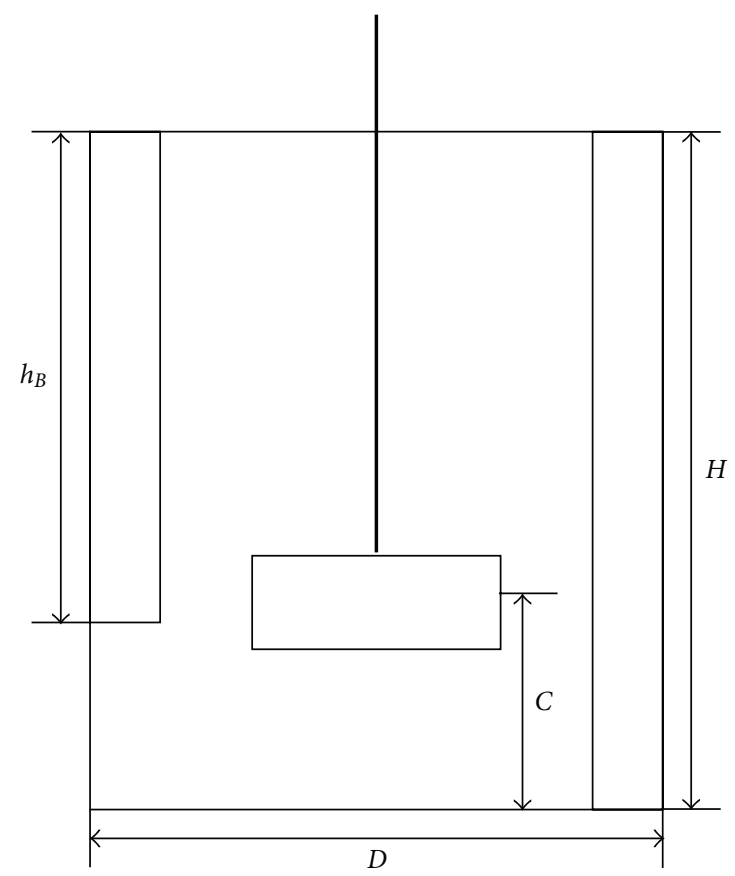

FIGURE 3: Geometry of mixing vessel.

from 60 to $540 \mathrm{rpm}$ to avoid a large vortex at the center of the free surface of the liquid.

\section{Results and Discussion}

3.1. Paddle Impeller. The correlation equations of Table 1 were developed by Kamei et al. [4, 5] for paddle and Rushton turbine impellers. The comparison between experimental values and calculated values were shown in Figure 4 . The correlation equations in Table 1 reproduced the experimental results better than Nagata's correlation equations for the wide range of impeller. The correlation equations for the pitched paddle impeller were shown in Table 2 . The correlation equations also reproduced experimental values, which were not shown in a figure here.

3.2. Propeller and Pfaudler Impellers. The blades of the propeller and pfaudler impellers do not have sharp edges. The laminar term $C_{L}$ in Table 1 can be used without modification. Because the deviation from correlations to measured values in the turbulent region was large, the turbulent terms $C_{t}$ and $m$ in Table 1 were modified by Kato et al. [7] based on fitting with the modified Reynolds number $\operatorname{Re}_{G}$ and the friction factor $f$, as follows:

$$
\begin{gathered}
C_{t}=\left[\left(3 X^{1.5}\right)^{-7.8}+(0.25)^{-7.8}\right]^{-1 / 7.8}, \\
m=\left[\left(0.8 X^{0.373}\right)^{-7.8}+(0.333)^{-7.8}\right]^{-1 / 7.8} .
\end{gathered}
$$

Figures 5 and 6 show the values correlated by the equations in Table 3 and the measured ones. The same equations can be used for the propeller- and the pfaudler-type impellers, regardless of the clearance between the vessel bottom and impeller. 


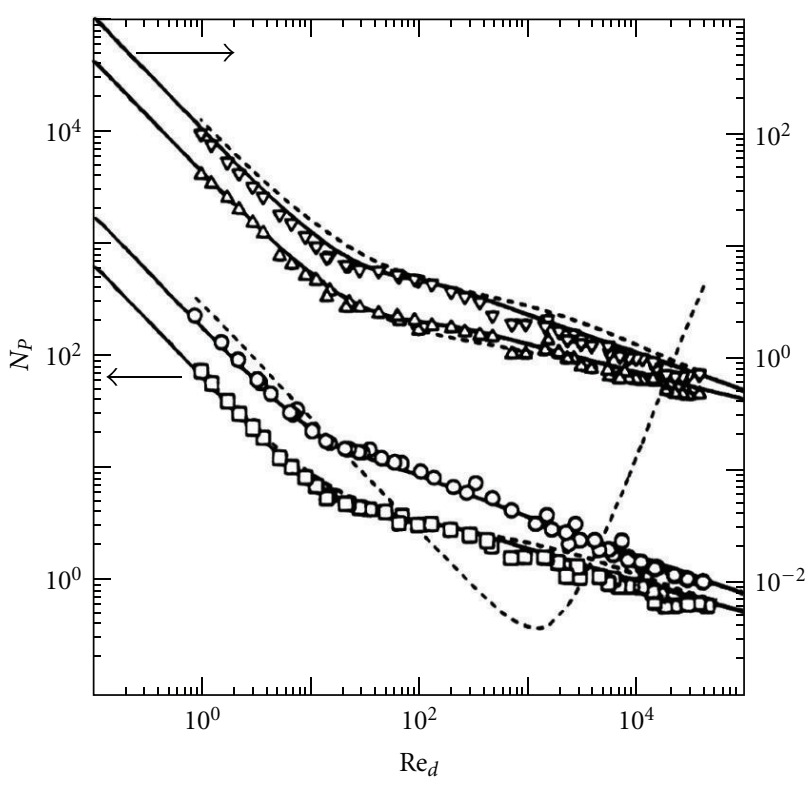

$\begin{array}{cccc} & d / D & b / D & n_{p} \\ \nabla & 0.585 & 0.146 & 8 \\ \bigcirc & 0.447 & 0.447 & 6 \\ \square & 0.524 & 0.131 & 4 \\ \triangle & 0.585 & 0.146 & 2\end{array}$

Figure 4: Power diagram of paddle impeller (- - - [3]; - [4, 5]).

TABLE 1: Correlation equations of power number for paddle (a), Rushton turbine (c) and anchor (f).

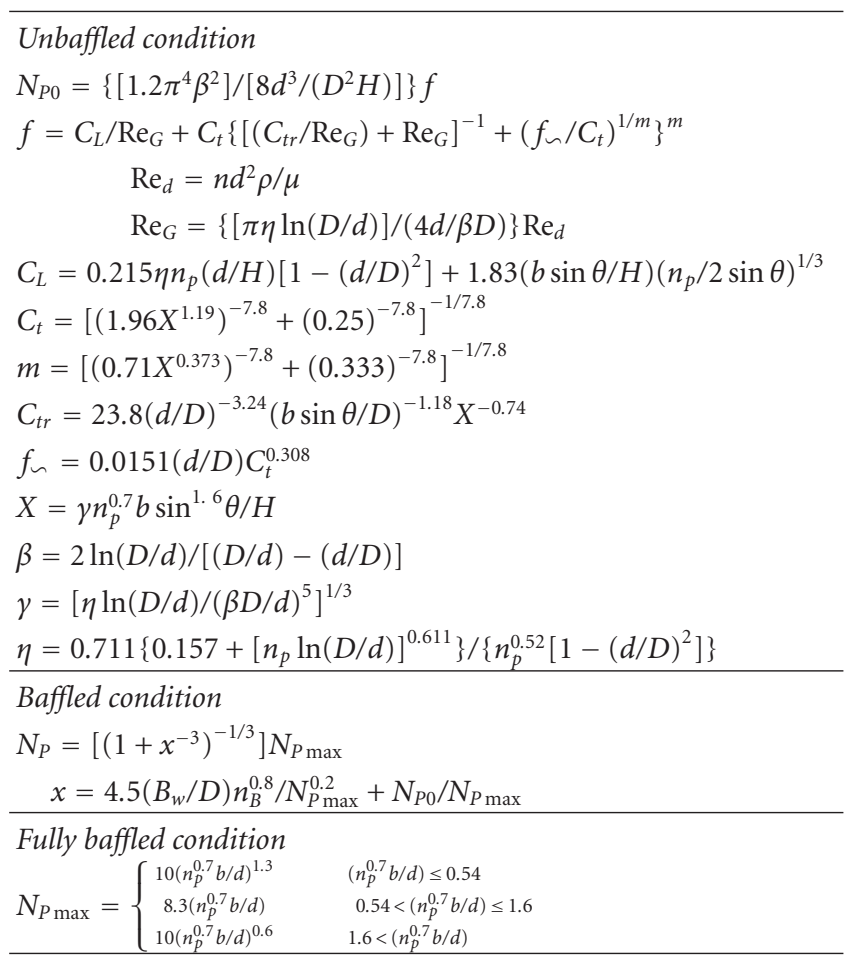

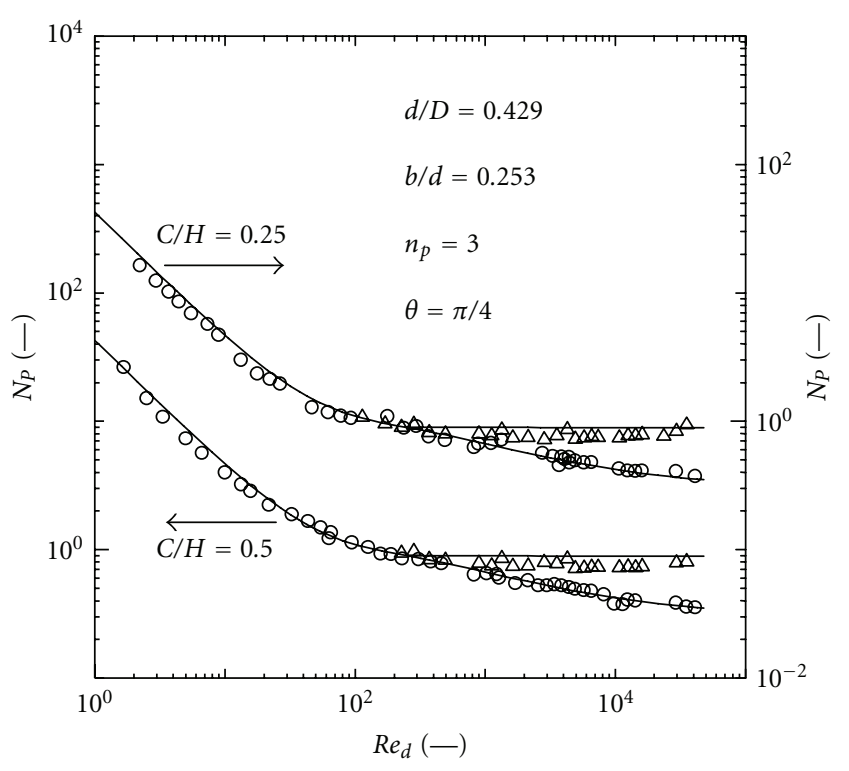

FIGURE 5: Power diagram of propeller impeller (- calc; $\bigcirc N_{P 0} ; \triangle$ $N_{P}$ ).

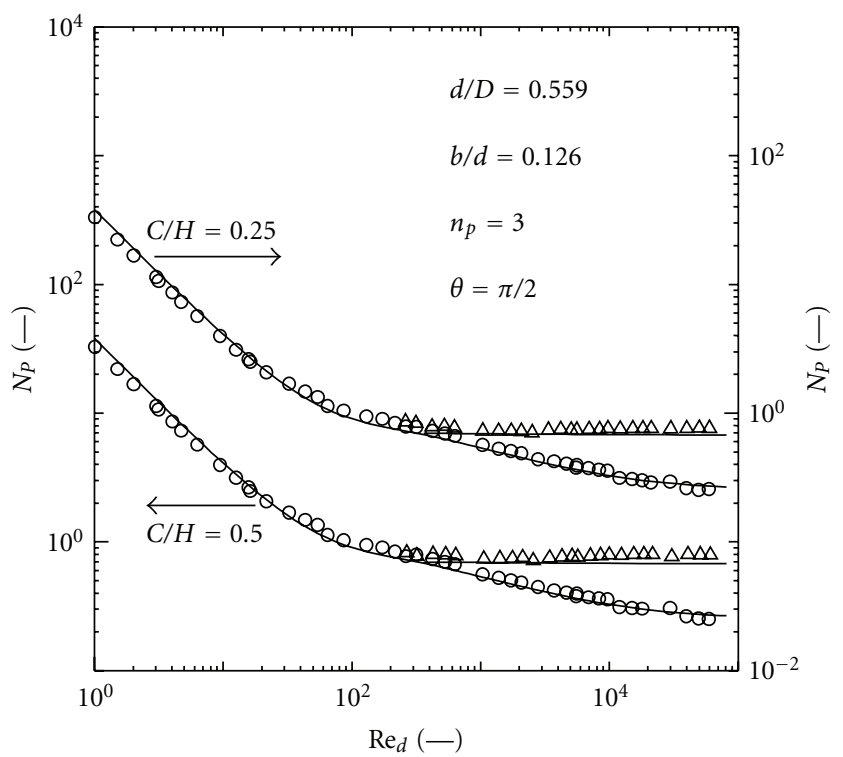

FIGURE 6: Power diagram of pfaudler-type impeller (— calc; $\bigcirc N_{P 0}$; $\left.\triangle N_{P}\right)$.

3.3. Anchor Impeller. The anchor impeller was used for the high-viscosity liquid normally. In this work, power consumption for an anchor impeller was measured in a wide range of Reynolds numbers from laminar to turbulent flow regions. In the laminar region, the power number of the anchor was reproduced by the correlations of Nagata and Kamei et al. by considering the anchor as a wide paddle impeller. In the turbulent region, it was reproduced by the correlation of Kamei et al. [4] without the correction of the parameters as shown in Figure 7 [8]. If a large vortex was generated in a turbulent mixing vessel, the experimental values of power number were larger than the calculated ones. 


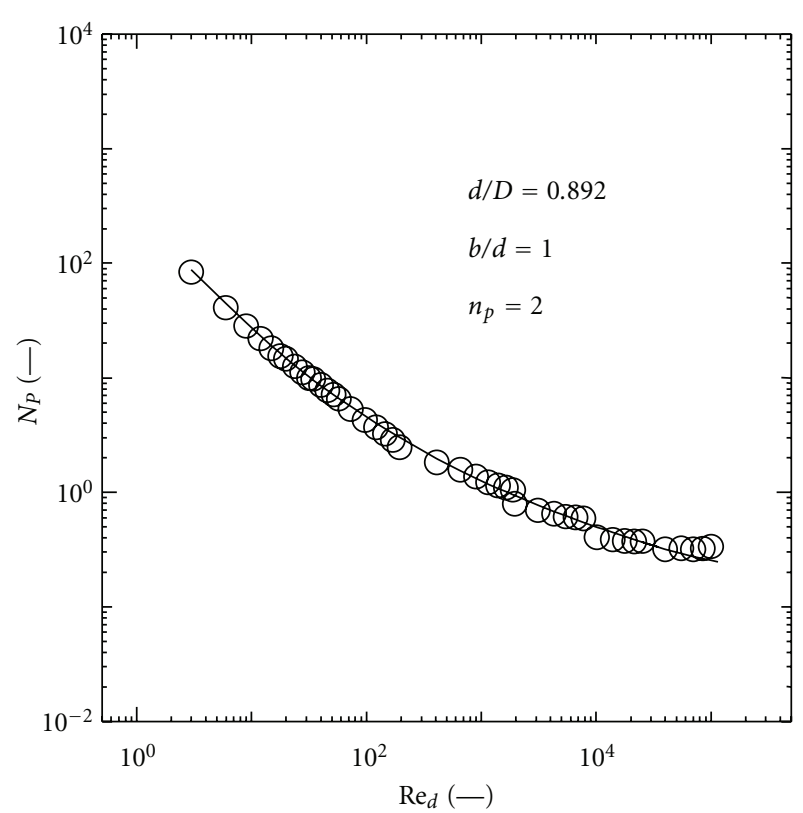

FIgURE 7: Power diagram of anchor impeller $\left(-\right.$ calc; $\left.\bigcirc N_{P 0}\right)$.

TABLE 2: Correlation equations of power number for pitched paddle (b).

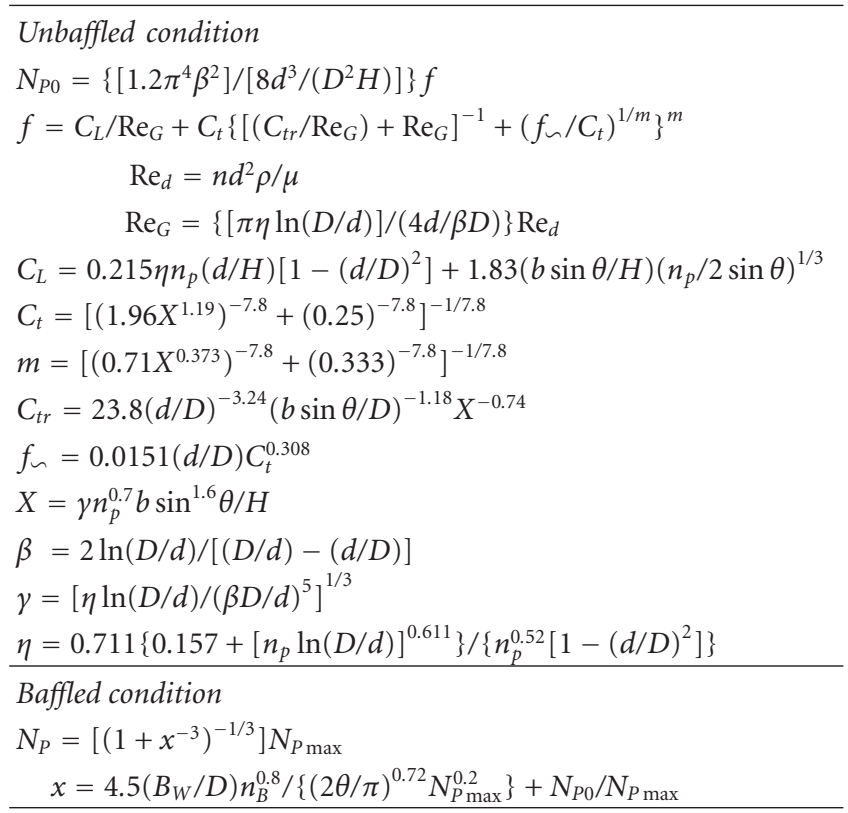

Fully baffled condition

$N_{P \max }=8.3(2 \theta / \pi)^{0.9}\left(n_{p}^{0.7} b \sin ^{1.6} \theta / d\right)$

3.4. Helical-Ribbon Impeller. As an example applied to a helical-ribbon impeller the correlation by Kamei et al. [4] was shown in Figure 8. Since it is the special case, the values of the equations for fitting the experimental values were shown in Table 4. It is the first time to show the power correlation of the helical-ribbon impeller over the wide range of Reynolds numbers.
TABLE 3: Correlation equations of power number for propeller (d) and pfaudler (f).

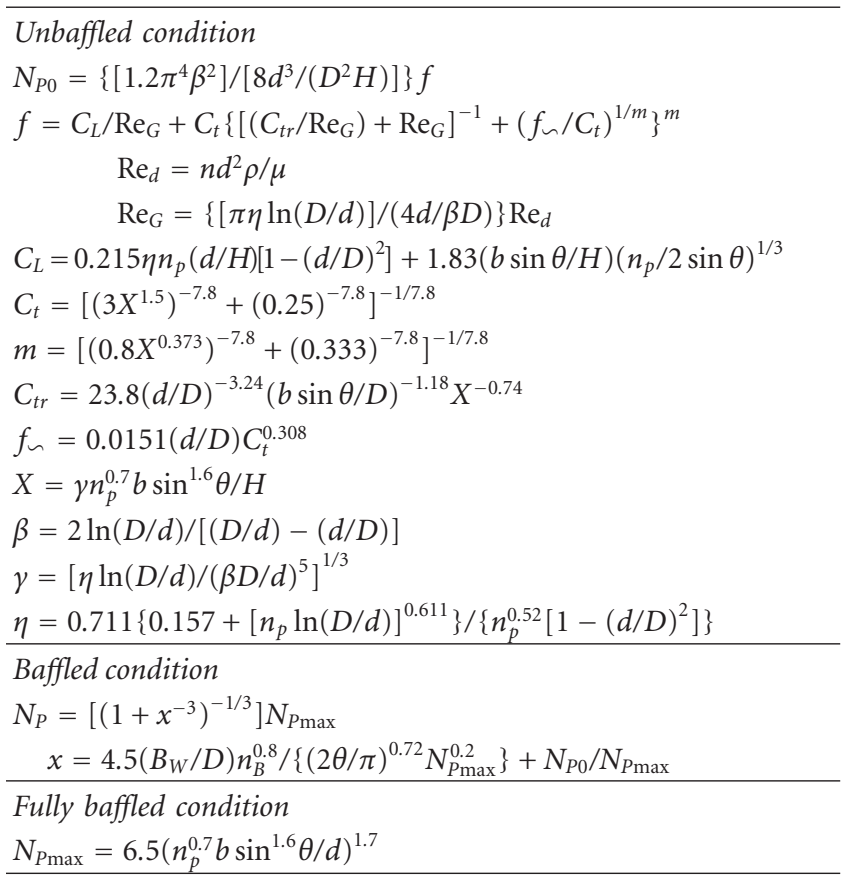

TABLE 4: Correlation equations of power number for helical ribbon (g).

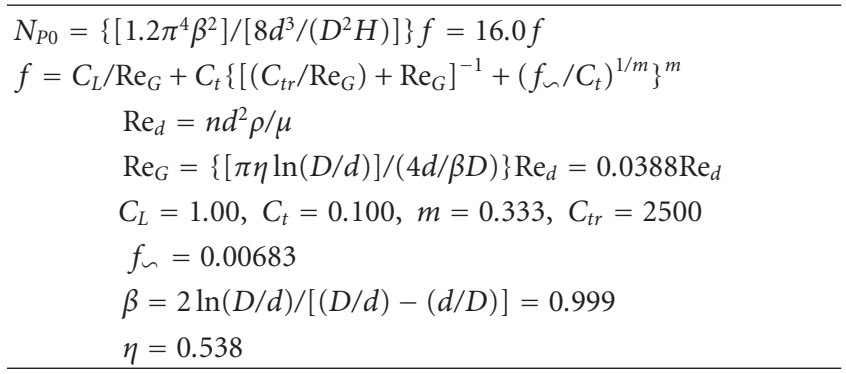

3.5. Pitched Paddle and Propeller Impellers with Partial Baffle. The effects of the baffle length on the power consumption of a mixing vessel with several impellers were studied as shown in Figure 3. The power number was generally correlated with the baffle length, the number of baffles, and the baffle width [9]. The power number of the pitched paddle and the propeller impellers was correlated with only the correction as follows,

$$
\begin{gathered}
N_{P}=\left[\left(1+x^{-3}\right)^{-1 / 3}\right] N_{P \max } \\
x=\frac{4.5\left(B_{W} / D\right) n_{B}^{0.8}\left(h_{B} / H\right)}{\left\{(2 \theta / \pi)^{0.72} N_{P \max }^{0.2}\right\}}+\frac{N_{P 0}}{N_{P \max }},
\end{gathered}
$$

the results were shown in Figure 9.

3.6. Comparison of Power Number of Propeller Impeller with Rushton's Data. Figure 10 shows the comparison of power number of a propeller impeller by Rushton et al. [10] with correlation in Table 3 . The correlation equations in Table 3 


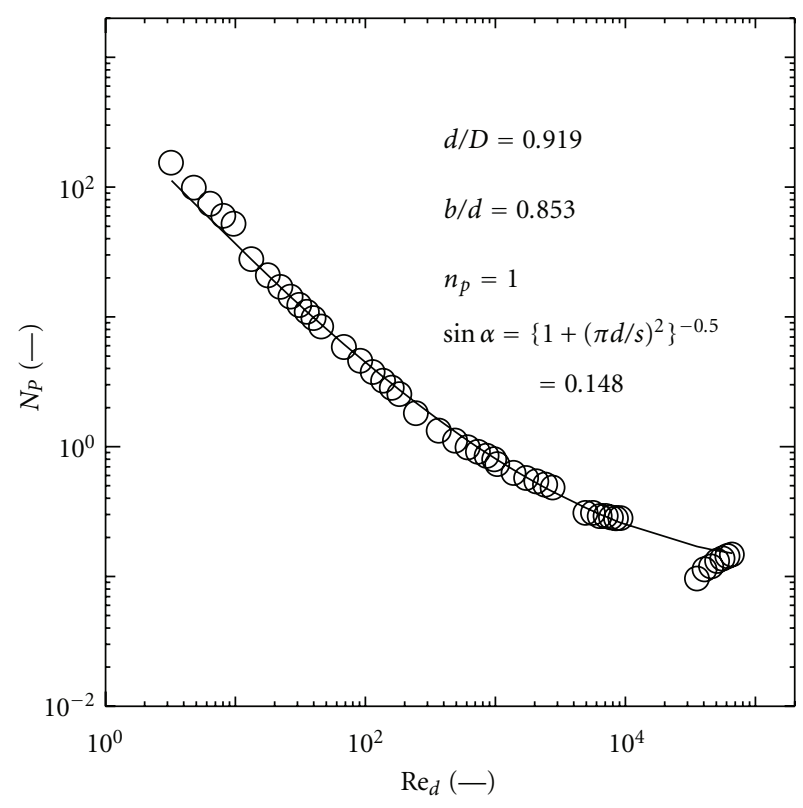

Figure 8: Power diagram of helical ribbon-impeller ( - calc; $\bigcirc$ $\left.N_{P 0}\right)$.

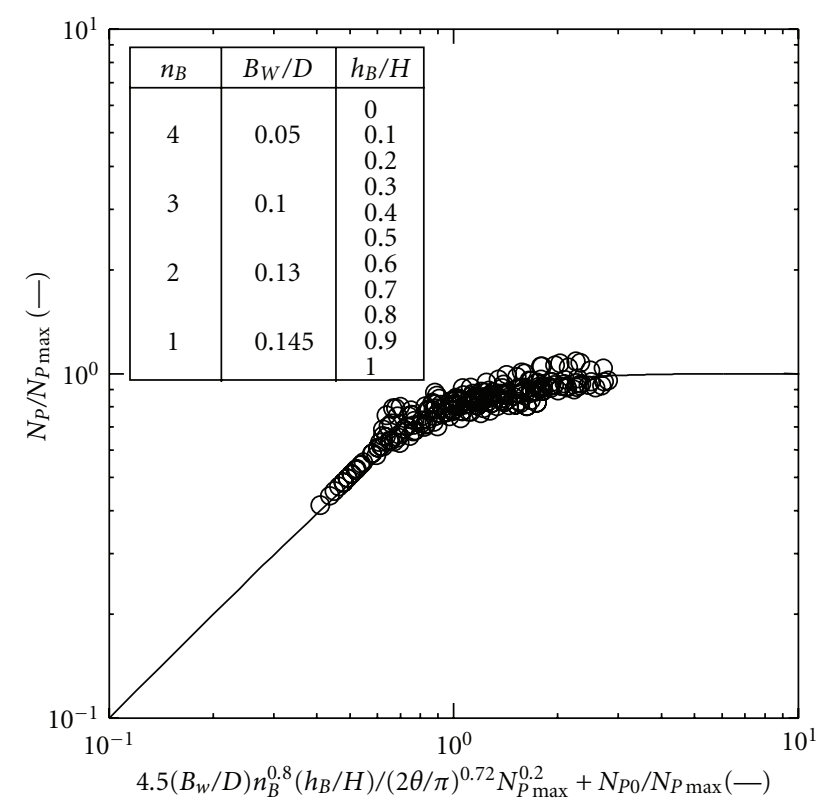

FIGURE 9: Correlation of power number for propeller with partial baffle (— calc; $\bigcirc$ exp.).

also reproduced the data which other researchers measured well. As mentioned above, the correlation reproduced in this work has a possibility of correlating the power number of the mixing impellers of all geometry. It is the first time to compare between the data of Rushton's and the power correlation over the wide range of Reynolds number.

\section{Conclusions}

The authors reviewed the power correlations developed by authors. The new correlation equations of power number,

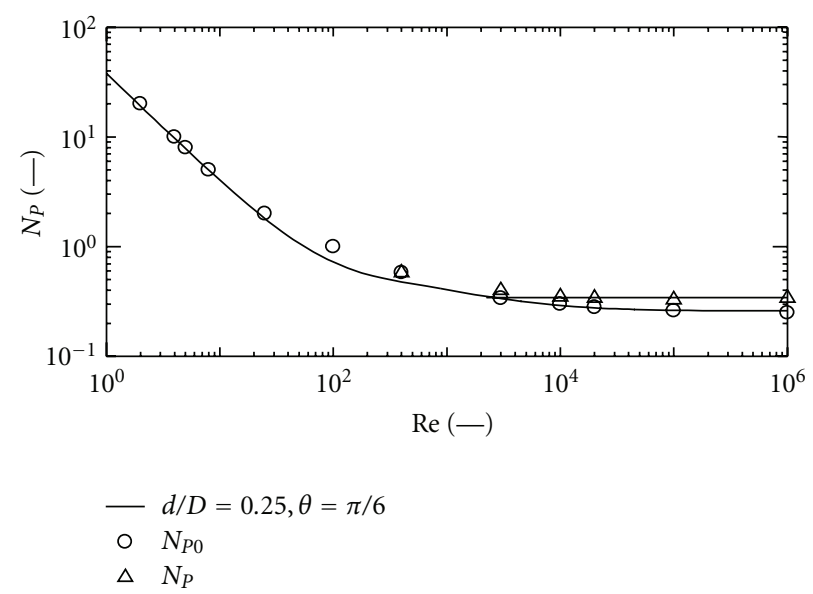

Figure 10: Comparison of power number for propeller with Rushton's data (— calc; $\bigcirc, \triangle$ Rushton's).

based on the correlation of Kamei and Hiraoka, were developed for several kinds of mixing impellers, and it was shown that the calculated values of the power number agreed very closely with the measured ones. In future work, this correlation will be expanded to other impellers.

\section{Nomenclature}

$b$ : $\quad$ Height of impeller blade $(\mathrm{m})$

C: $\quad$ Clearance between bottom and impeller $(\mathrm{m})$

$D: \quad$ Vessel diameter $(\mathrm{m})$

$d: \quad$ Impeller diameter $(\mathrm{m})$

$f: \quad$ Friction factor $(-)$

$H: \quad$ Liquid depth $(\mathrm{m})$

$h_{B}: \quad$ Baffle length $(\mathrm{m})$

$N_{P}: \quad$ Power number $\left(=P / \rho n^{3} d^{5}\right)(-)$

$N_{P 0}$ : Power number in unbaffled condition $(-)$

$N_{P_{\max }}$ : Power number in fully baffled condition (-)

$n: \quad$ Impeller rotational speed (-)

$n_{B}: \quad$ Number of baffle plates $(-)$

$n_{p}: \quad$ Number of impeller blades $(-)$

$P: \quad$ Power consumption (W)

$\mathrm{Re}_{d}: \quad$ Impeller Reynolds number $\left(=n d^{2} \rho / \mu\right)(-)$

$\mathrm{Re}_{G}$ : Modified Reynolds number (-)

T: $\quad$ Shaft torque $(\mathrm{N} \cdot \mathrm{m})$

$\theta: \quad$ Angle of impeller blade (-)

$\mu: \quad$ Liquid viscosity $(\mathrm{Pa} \cdot \mathrm{s})$

$\rho: \quad$ Liquid density $\left(\mathrm{kg} / \mathrm{m}^{3}\right)$.

\section{References}

[1] Y. Inoue and S. Hashimoto, "Analysis of mechanism of laminar fluid mixing in 3-D mixing tank based on streakline lobes," Kagaku Kogaku Ronbunshu, vol. 36, no. 4, pp. 355-365, 2010.

[2] Y. Inoue, "Invariant structure and variable properties in laminar fluid mixing model based on strealines," Kagaku Kogaku Ronbunshu, vol. 37, pp. 211-222, 2011.

[3] S. Nagata, T. Yokoyama, and H. Maeda, "Studies on the power requirement of paddle agitators in cylindrical vessels," Kagaku Kogaku, vol. 20, pp. 582-592, 1956. 
[4] N. Kamei, S. Hiraoka, Y. Kato et al., "Power correlation for paddle impellers in spherical and sylindrical agitated vessels," Kagaku Kogaku Ronbunshu, vol. 21, pp. 41-48, 1995.

[5] N. Kamei, S. Hiraoka, Y. Kato et al., "Effects of impeller and baffle dimensions on power consumption under turbulent flow in an agitated vessel with paddle impeller," Kagaku Kogaku Ronbunshu, vol. 22, no. 2, pp. 255-256, 1996.

[6] S. Hiraoka, N. Kamei, and Y. Kato, "Power correlation for pitched blade paddle impeller in agitated vessels with and without baffles," Kagaku Kogaku Ronbunshu, vol. 23, no. 6, pp. 974-975, 1997.

[7] Y. Kato, Y. Tada, Y. Takeda, Y. Hirai, and Y. Nagatsu, "Correlation of power consumption for propeller and pfaudler type impellers," Journal of Chemical Engineering of Japan, vol. 42, no. 1, pp. 6-9, 2009.

[8] Y. Kato, N. Kamei, Y. Tada et al., "Power consumption of anchor impeller over wide range of reynolds number," Kagaku Kogaku Ronbunshu, vol. 37, pp. 19-21, 2011.

[9] Y. Kato, N. Kamei, A. Tada et al., "Effect of baffle length on power consumption in turbulent mixing vessel," Kagaku Kogaku Ronbunshu, vol. 37, pp. 377-380, 2011.

[10] J. H. Rushton, E. W. Costich, and H. J. Everett, "Power characteristics of mixing impellers part 1," Chemical Engineering Progress, vol. 46, no. 8, pp. 395-404, 1950. 

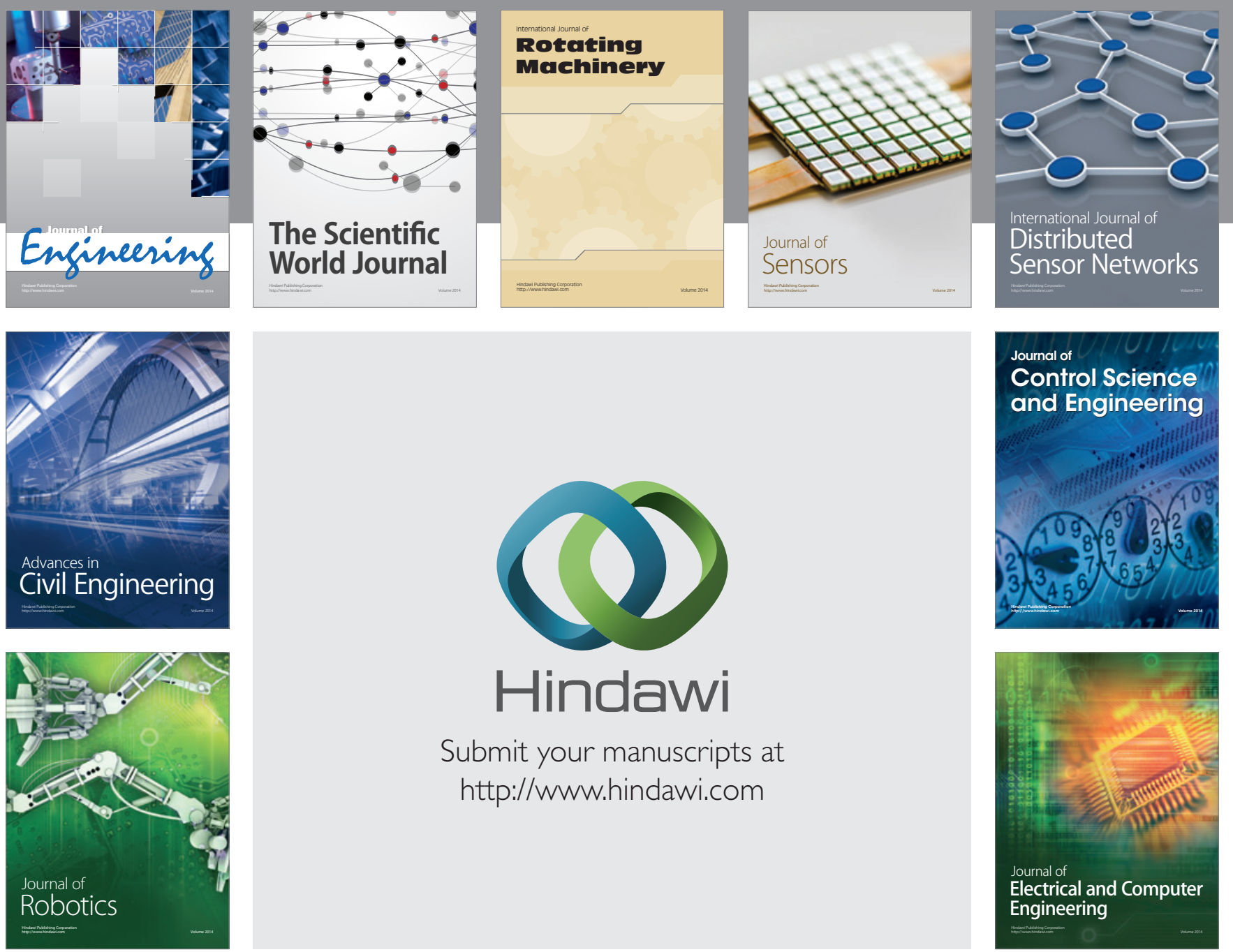

Submit your manuscripts at

http://www.hindawi.com
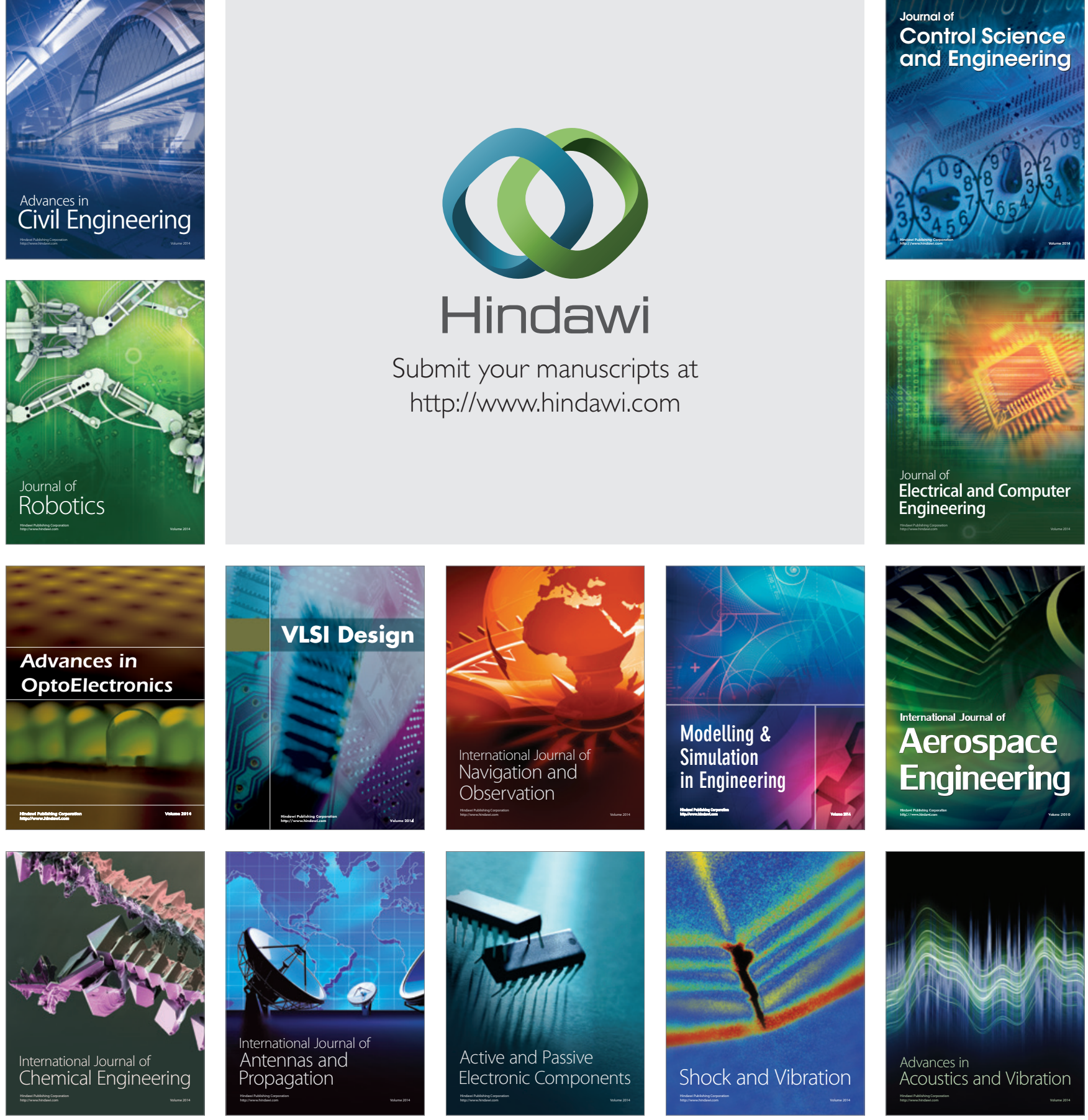